\title{
Functional Assembly of a Microbial Consortium with Autofluorescent and Mineralizing Activity for the Biodegradation of Organophosphates
}

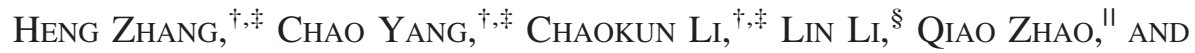 \\ CHUANLING QIAO* ${ }^{\dagger} \dagger$
}

\begin{abstract}
State Key Laboratory of Integrated Management of Pest Insects \& Rodents, Institute of Zoology, Chinese Academy of Sciences, Beijing 100101, China, Graduate School of the Chinese Academy of Sciences, Beijing 100049, China, State Key Laboratory of Environmental Aquatic Chemistry, Research Center for Eco-Environmental Sciences, Chinese Academy of Sciences, Beijing 100085, China, and Plant Biotechnology Center and Department of Plant Cellular and Molecular Biology, The
\end{abstract} Ohio State University, Columbus, Ohio 43210

\begin{abstract}
Organophosphorus pesticides (OPs) cause serious environmental problems, and bioremediation using bacterial enzymes may provide an efficient and economical method for their detoxification. Green fluorescent protein (GFP) is a stable and easily detectable marker in monitoring genetically engineered microorganisms (GEMs) in the environment. In our research, the methyl parathion hydrolase gene $(m p d)$ and enhanced green fluorescent protein gene (egfp) were successfully coexpressed using pETDuet vector in E. coli BL21 (DE3). The coexpression of methyl parathion hydrolase (MPH) and enhanced green fluorescent protein (EGFP) were confirmed by determining MPH activity and fluorescence intensity. The recombinant protein MPH showed high enzymatic degradative activity of several widely used OP residues on vegetables determined by GC analysis. Subsequently, a dualspecies consortium comprising engineered $E$. coli and a natural $p$-nitrophenol (PNP) degrader Ochrobactrum sp. strain LL-1 for complete mineralization of dimethyl OPs was studied. It could completely mineralize methyl parathion (MP) via MP through PNP and hydroquinone and eventually through the TCA cycle as determined by HPLC analysis. The accumulation of PNP in suspended culture was prevented. The consortium could be further utilized for complete mineralization of PNPsubstituted OPs in a laboratory-scale bioreactor and easily monitored by fluorescence of EGFP for its activity and fate.
\end{abstract}

KEYWORDS: Methyl parathion hydrolase; coexpression; organophosphate; green fluorescent protein; microbial consortium

\section{INTRODUCTION}

Synthetic organophosphorus compounds are used extensively in agricultural and domestic pest control. However, mass application of these compounds in the environment causes serious environmental problems. Organophosphorus pesticides (OPs) cause enormous damage to nontarget organisms because acetylcholinesterase is present in all vertebrates (1).

Bioremediation of organophosphate compounds in the environment using bacterial enzymes may provide an efficient,

To whom correspondence should be addressed. Tel: 86-10-64807191. Fax: 86-10-64807099. E-mail: qiaocl@ioz.ac.cn.

${ }^{\dagger}$ State Key Laboratory of Integrated Management of Pest Insects \& Rodents, Chinese Academy of Sciences.

* Graduate School of the Chinese Academy of Sciences.

${ }^{\S}$ State Key Laboratory of Environmental Aquatic Chemistry, Chinese Academy of Sciences.

"The Ohio State University. convenient, and economical method for detoxification. Organophosphorus hydrolase (OPH), isolated from both Flavobacterium sp. ATCC 27551 (2) and Pseudomonas diminuta MG (3), is capable of hydrolyzing a wide range of oxon and thion OPs. However, OPH has already been shown to lack any hydrolytic activity toward numerous dimethyl OPs (4). The mpd gene encoding an organophosphate degrading protein was isolated from a methyl parathion (MP) degrading Plesiomonas sp. and showed no homology to the opd genes (5). Changes in substrate specificity have been reported for MPH, which exhibits higher $K_{\text {cat }} / K_{\mathrm{m}}$ values for dimethyl OPs such as MP $(6,7)$.

Enumerating and assessing of genetically engineered microorganisms (GEMs) in polluted soil and aquatic environments can be assisted by using stable marker systems with an easily detectable phenotype. The green fluorescent protein (GFP) is a unique marker that can emit bright green fluorescence after UV light or visible light excitation $(8,9)$. GFP was introduced into microbes without influencing the metabolism of the various 


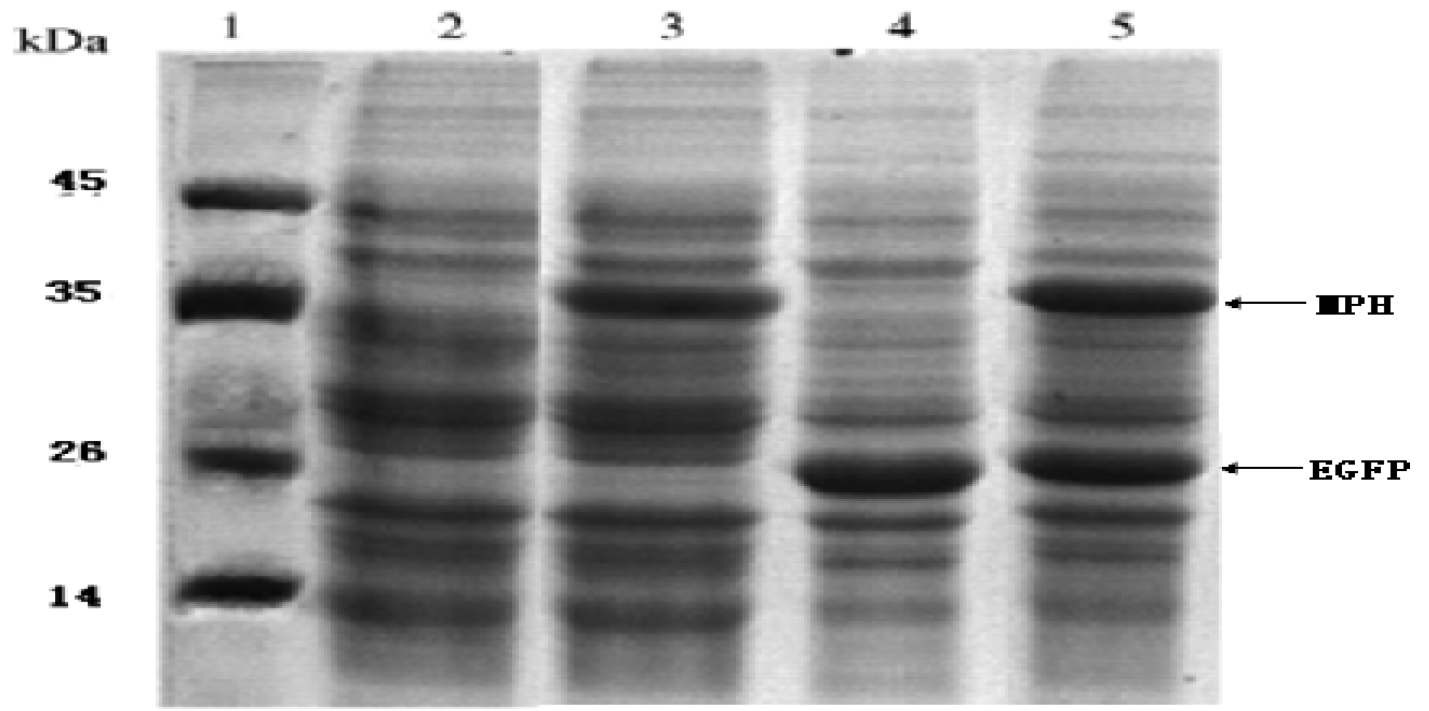

Figure 1. 12\% SDS-PAGE analysis of recombinant proteins coexpressed in E. coli BL21(DE3). Lane 1, protein molecular weight standards; lane 2, whole cell lysates of induced E. coli harboring plasmid pETDuet; lane 3, expression of MPH in E. coli carrying pETDM; lane 4, expression of EGFP in E. coli carrying pETDG; lane 5, expression of MPH and EGFP in E. coli carrying pETDMG. The molecular masses of standards are shown in the left margin.

Table 1. MPH Activity and Fluorescence Intensity of E. coli BL21 (DE3) Harboring pETDMG Plasmid Induced by Different Concentrations of IPTG for $8 \mathrm{~h}$ at $30^{\circ} \mathrm{C}^{a}$

\begin{tabular}{lccc}
\hline $\begin{array}{l}\text { sample } \\
\text { number }\end{array}$ & $\begin{array}{c}\text { concentration } \\
\text { of IPTG }(\mathrm{mM})\end{array}$ & $\begin{array}{c}\text { MPH activity } \\
\text { (U/mg protein) }\end{array}$ & $\begin{array}{c}\text { fluorescence } \\
\text { intensity }\end{array}$ \\
\hline 1 & 0.05 & $7.52 \pm 0.24$ & $4410 \pm 28$ \\
2 & 0.1 & $16.05 \pm 0.33$ & $7739 \pm 25$ \\
3 & 0.2 & $16.46 \pm 0.29$ & $7644 \pm 36$ \\
4 & 0.3 & $16.49 \pm 0.31$ & $7991 \pm 41$ \\
5 & 0.4 & $17.02 \pm 0.37$ & $7998 \pm 19$ \\
6 & 0.5 & $16.95 \pm 0.41$ & $7892 \pm 22$ \\
7 & 0.6 & $16.69 \pm 0.37$ & $8032 \pm 26$ \\
8 & 0.7 & $16.65 \pm 0.42$ & $7910 \pm 36$ \\
9 & 0.8 & $16.53 \pm 0.23$ & $7910 \pm 36$ \\
10 & 0.9 & $16.82 \pm 0.39$ & $7795 \pm 35$ \\
& & & \\
\hline
\end{tabular}

${ }^{a}$ Error bars represent standard the deviation from three independent experiments.

hosts $(10-12)$. As a marker for ecological studies, GFP requires no cofactors but $\mathrm{O}_{2}$ for fluorescence (13), making it ideal for monitoring GEMs in the environment (14-17).

$p$-Nitrophenol (PNP) is an environmental pollutant and the major metabolite from dimethyl OPs (e.g., MP, parathion) $(2,18)$. In order to completely mineralize OPs, a strategy is to target OPH or MPH onto the outer membrane of a natural PNP degrader, which results in a bacterium with both OPH or MPH activity and PNP mineralization capability $(7,18-20)$. While the engineered strain was endowed with MP mineralizing activity, the use of displayed OPH or MPH may increase the metabolic burden of the host strain. The other feasible way of constructing a complete degradation pathway in a single microbe is to combine bacteria with complementary metabolic pathways into functional assemblages in coculture. Several xenobiotic pollutants, including chlorinated dibenzofurans (21), 9-fluorenone (22), parathion (23), and chlorpyrifos (24), have been reported to be completely mineralized using this approach.

We previously cloned the mpd gene (GenBank accession number DQ677027) from a chlorpyrifos-degrading bacterium and expressed the gene in E. coli (25). Recently, we have isolated an Ochrobactrum sp. named LL-1 (resistant to ampicillin) capable of utilizing high concentrations of PNP (up to $0.8 \mathrm{mM}$ ) as the sole source of carbon, nitrogen, and energy from an activated sludge. In the present study, MPH
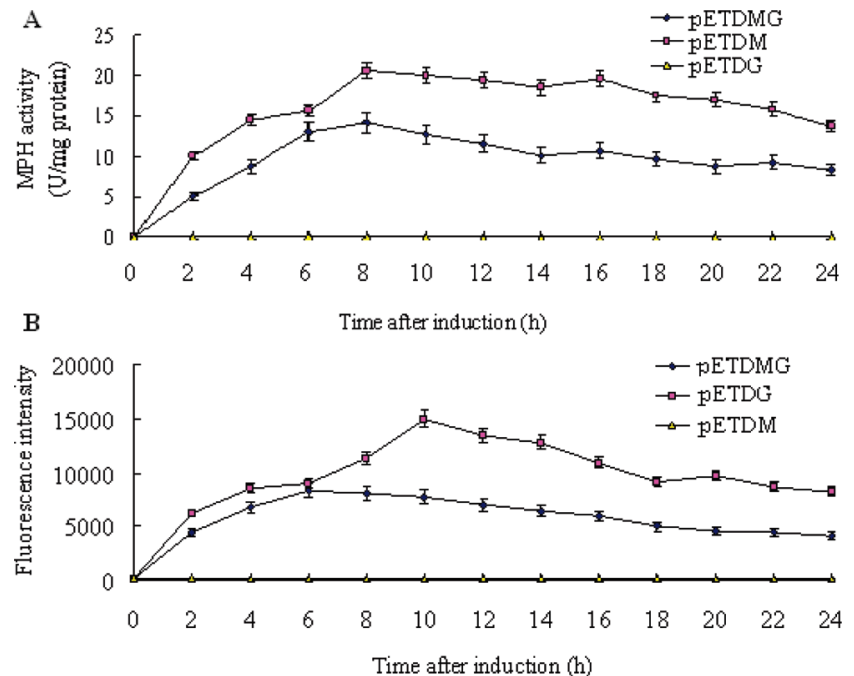

Figure 2. Time course analysis of MPH activity (A) of total cellular protein (TCP) and fluorescence intensity $(B)$ of whole-cells of $E$. coli $\mathrm{BL} 21$ (DE3) induced by IPTG for $24 \mathrm{~h}$ at $30^{\circ} \mathrm{C}$. Error bars represent the standard deviation from three independent experiments.

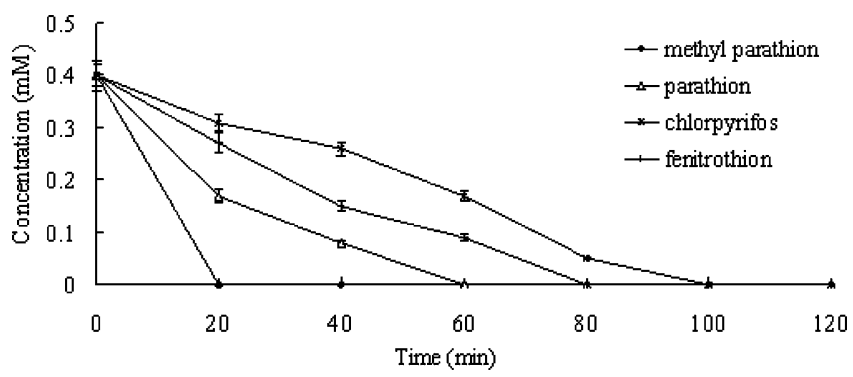

Figure 3. Degradation of OP residues on cabbage leaves by MPH of total cellular protein (TCP) of E. coli BL21 (DE3). Error bars represent the standard deviation from three independent experiments.

and EGFP were successfully coexpressed using the pETDuet vector in E. coli. The detoxification of MP, parathion, chlorpyrifos, and fenitrothion residues on cabbage leaves by MPH was studied. A dual-species consortium was developed for complete mineralization of MP. The consortium was 


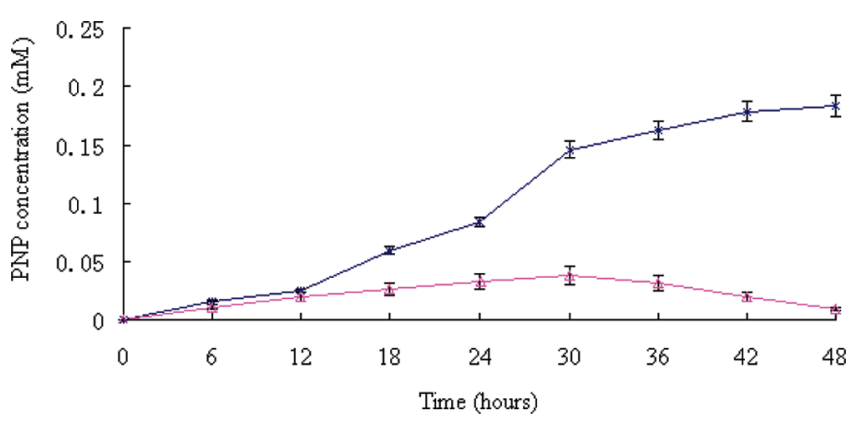

Figure 4. PNP accumulation and metabolism during MP biodegradation by suspended cells. $(\times)$ Escherichia coli BL21, $(\square)$ mixed culture of $E$. coli BL21 and Ochrobactrum sp. strain LL-1. Error bars represent the standard deviation from three independent experiments.

cocultured in LB medium, and the effect of PNP on growth was studied.

\section{MATERIALS AND METHODS}

Bacterial Strains and Plasmids. E. coli strain BL-21 (DE3) $\left(\mathrm{F}^{-}\right.$ ompT hsd $S_{\mathrm{B}}\left(\mathrm{r}_{\mathrm{B}}{ }^{-} \mathrm{m}_{\mathrm{B}}{ }^{-}\right)$gal dcm (DE3), Novagen, USA) was used as the expression host throughout the experiments. Ochrobactrum sp. LL1 , a natural PNP strain, was cocultured with $E$. coli. Plasmid pETDuet (Novagen, USA) was used for coexpressing the $m p d$ gene and the $e g f p$ gene. Plasmids were maintained and propagated in E. coli DH5 $\alpha$ according to Sambrook et al. (26). Plasmid pMDQ (25) was used as the source of the mpd gene. pEGFP-N3 (Clontech, USA) was used as the source of the egfp gene. T4 DNA ligase, isopropyl thiogalactoside, ampicillin, and restriction enzymes were purchased from TaKaRa Biotechnology Co. Ltd. (Dalian, China).

Media and Culture Conditions. Strains bearing plasmids were grown in Luria-Bertani (LB) medium supplemented with ampicillin to a final concentration of $50 \mu \mathrm{g} \mathrm{mL}^{-1}$. Cells were grown at various temperatures in $250 \mathrm{~mL}$ flasks in a shaker with vigorous agitation (260 $\mathrm{rpm})$. Bacteria harboring expression vectors were grown to an $\mathrm{OD}_{600}$ $=0.6$ before induction with IPTG. The cells continued to grow under different concentrations of IPTG $(0.05-1.0 \mathrm{mM})$ or different induction times $(0-24 \mathrm{~h})$.

Construction of the Expression Plasmids. To construct a mature MPH and EGFP coexpression plasmid, $m p d$ without signal sequence and the egfp gene were amplified using PCR. The region encoding mature MPH was amplified from plasmid pMDQ with forward primer 5'-GGATCCCATGGCCGCACCGCAGGTG-3' and reverse primer 5'AAGCTTTCACTTGGGGTTGACGAC-3' (the HindIII and BamHI sites, respectively, are underlined). The PCR fragment was subsequently cloned into the BamHI-HindIII restriction sites of pETDuet to generate the recombinant plasmid pETDuet-mpd (pETDM). The $g f p$ gene was amplified from plasmid pEGFP-N3 with forward primer 5'-CATATGATGGTGAGCAAGGGCGAG-3' and reverse primer 5'-GGTACCCT- TGTACAGCTCGTCCAT-3' (the NdeI and KpnI sites, respectively, are underlined). The PCR fragment was subsequently cloned into the NdeI-KpnI restriction sites of pETDM to generate the recombinant plasmid pETDuet-mpd-egfp (pETDMG). At the same time, the $g f p$ gene was also cloned into the NdeI-KpnI restriction sites of pETDuet to generate the recombinant plasmid pETDuet-egfp (pETDG) as the control. The correct sequence of the insert was confirmed by sequencing.

Expression of the Recombinant Protein in E. coli and Preparation of Total Cellular Protein (TCP). Expression studies were carried out using E. coli $\mathrm{BL}-21$ (DE3). Transformation was performed using the $\mathrm{MgCl}_{2}$ or $\mathrm{CaCl}_{2}$ method (26). The vectors of pETDMG, pETDM, and $\mathrm{pETDG}$ were transformed. The bacteria for expression of the recombinant proteins were incubated overnight at $37^{\circ} \mathrm{C}$ in $\mathrm{LB}$ medium containing $50 \mu \mathrm{g} \mathrm{mL}^{-1}$ ampicillin and then transferred into the same medium and continuously grown at $37{ }^{\circ} \mathrm{C}$ in a shaker until bacteria were grown to an $\mathrm{OD}_{600}=0.6$. The cultures were induced with 0.1 mM IPTG for $8 \mathrm{~h}$ at $30{ }^{\circ} \mathrm{C}$. Total cellular protein (TCP) of samples was prepared for analysis as follows: cells were harvested, washed with $100 \mathrm{mM}$ phosphate/buffered saline (PBS, pH 7.5), and then resuspended in one-fifth volume of the same buffer. The suspension was ultrasonicated on ice in three pulses of $10 \mathrm{~s}$ each. The TCP was determined by the Bradford method (27) with bovine serum albumin as a standard. Equal amounts of the TCP sample was assessed by $12 \%$ SDS-PAGE followed by Coomassie blue staining.

Determination of MPH Activity and Fluorescence Intensity. MPH activity was determined by the method of Yang et al. (7). TCP sample harboring pETDuet was used as background references. MPH activity assay mixtures ( $1 \mathrm{~mL}, 3 \%$ methanol) contained $50 \mu \mathrm{g} \mathrm{mL}{ }^{-1} \mathrm{MP}$ (added from a $10 \mathrm{mg} \mathrm{mL}^{-1}$ methanol stock solution), $960 \mu \mathrm{L}$ of $100 \mathrm{mM}$ phosphate buffer ( $\mathrm{pH} 7.4)$, and $10 \mu \mathrm{L}$ of TCP $\left(\mathrm{OD}_{600}=1.0\right)$. Changes in absorbance $(405 \mathrm{~nm})$ were measured for $3 \mathrm{~min}$ at $30{ }^{\circ} \mathrm{C}$. Activities were expressed as units ( $1 \mu \mathrm{mol}$ of PNP formed per minute) per milligram of protein $\left(\varepsilon_{405}=17,700 \mathrm{M}^{-1} \mathrm{~cm}^{-1}\right.$ for PNP).

Whole cells harboring pETDMG, pETDM, or pETDG were suspended in PBS buffer ( $\mathrm{pH} 7.5$ ) and diluted to $\mathrm{OD}_{600}=1.0$. The similarly diluted cells harboring pETDuet was used as background references. GFP fluorescence intensity was determined using a fluorescence spectrophotometer (F-4500, HITACHI, Japan) with a bandwidth of 5 $\mathrm{nm}$, excitation wavelength of $488 \mathrm{~nm}$, and emission wavelength of 510 nm.

Detoxification of OP Residues on Vegetable by MPH. TCP of samples was prepared in the same way as described above. Then, 10 $\mu \mathrm{L}$ of TCP $\left(\mathrm{OD}_{600}=1.0\right)$ was incubated with $0.4 \mathrm{mM}$ MP, parathion, chlorpyrifos, or fenitrothion.

The test samples were prepared as follows: $10 \mathrm{~g}$ of cabbage leaves was sprayed with a known amount of pesticide. After $3 \mathrm{~h}$, the contaminated sample was sprayed with TCP suspensions. Samples were collected at $0,20,40,60,80,100$, and $120 \mathrm{~min}$. These samples were chopped into fine pieces and then were homogenized with $30 \mathrm{~g}$ of anhydrous sodium sulfate in a blender with $30 \mathrm{~mL}$ of petroleum ether for $2 \mathrm{~min}$. The mixture was decanted and filtered through a $7 \mathrm{~cm}$ buchner funnel. The filter cake was washed twice with $10 \mathrm{~mL}$ of redistilled petroleum ether. The extracts were collected in a $150 \mathrm{~mL}$ flat-bottom flask, concentrated to almost dryness with a slight $\mathrm{N}_{2}$ stream, and diluted to $1 \mathrm{~mL}$ with redistilled petroleum ether for the determination by GC analysis.

Samples of $1 \mu \mathrm{L}$ (diluted if necessary) were analyzed using a Hewlett-Packard 5890 II GC (Hewlett-Packard, Wilmington, DE, USA) equipped with an ECD detector and a capillary HP-1 column (polydimethylsiloxane $25 \mathrm{~cm} \times 0.32 \mathrm{~mm} \times 0.25 \mu \mathrm{m}$ ). The uninoculated culture was used as a control. The detector, injector, and column temperatures were 300,300 , and $200{ }^{\circ} \mathrm{C}$, respectively. Column pressure was $7.7 \mathrm{psi}$, and column flow was $0.932 \mathrm{~mL} \mathrm{~min}^{-1}$. Under these conditions, the concentration of pesticides was determined by comparing peak area of the samples to a standard curve.

Coculture Study. Six flasks containing LB medium were supplemented with $50 \mu \mathrm{g} \mathrm{mL}^{-1}$ ampicillin, $1 \mathrm{mM}$ IPTG, and $0.2 \mathrm{mM} \mathrm{MP.}$ Three of the flasks were inoculated with E. coli BL21 (pETDMG). The remaining three flasks were inoculated with both $E$. coli BL21 (pETDMG) and strain LL-1. The initial $\mathrm{OD}_{600}$ of both strains inoculated was 0.04 . All cultures were grown with shaking at $30{ }^{\circ} \mathrm{C}$. At each time point, a $1 \mathrm{~mL}$ aliquot was withdrawn and centrifuged, and the supernatant was stored at $-20{ }^{\circ} \mathrm{C}$ for PNP analysis by HPLC (28).

\section{RESULTS}

Expression of MPH and EGFP. Expression of recombinant MPH and EGFP protein was detected by $12 \%$ SDS-PAGE (Figure 1). The calculated molecular weights of MPH and EGFP are 32 and $27 \mathrm{kDa}$, respectively. As expected, two bands of the recombinant protein were visualized at the right position by Coomassie Brilliant Blue staining in agreement with that calculated from the protein sequences. We can also observe that MPH and EGFP comprised about $32 \%$ and $35 \%$ of TCP by electrophoresis gel scanning, respectively. The data indicate that recombinant $\mathrm{MPH}$ and EGFP were expressed in E. coli BL21 (DE3) harboring pETDMG.

Enzymatic Activity and Fluorescence in the GEM. As shown in Table 1, except those samples induced by $0.05 \mathrm{mM}$ 


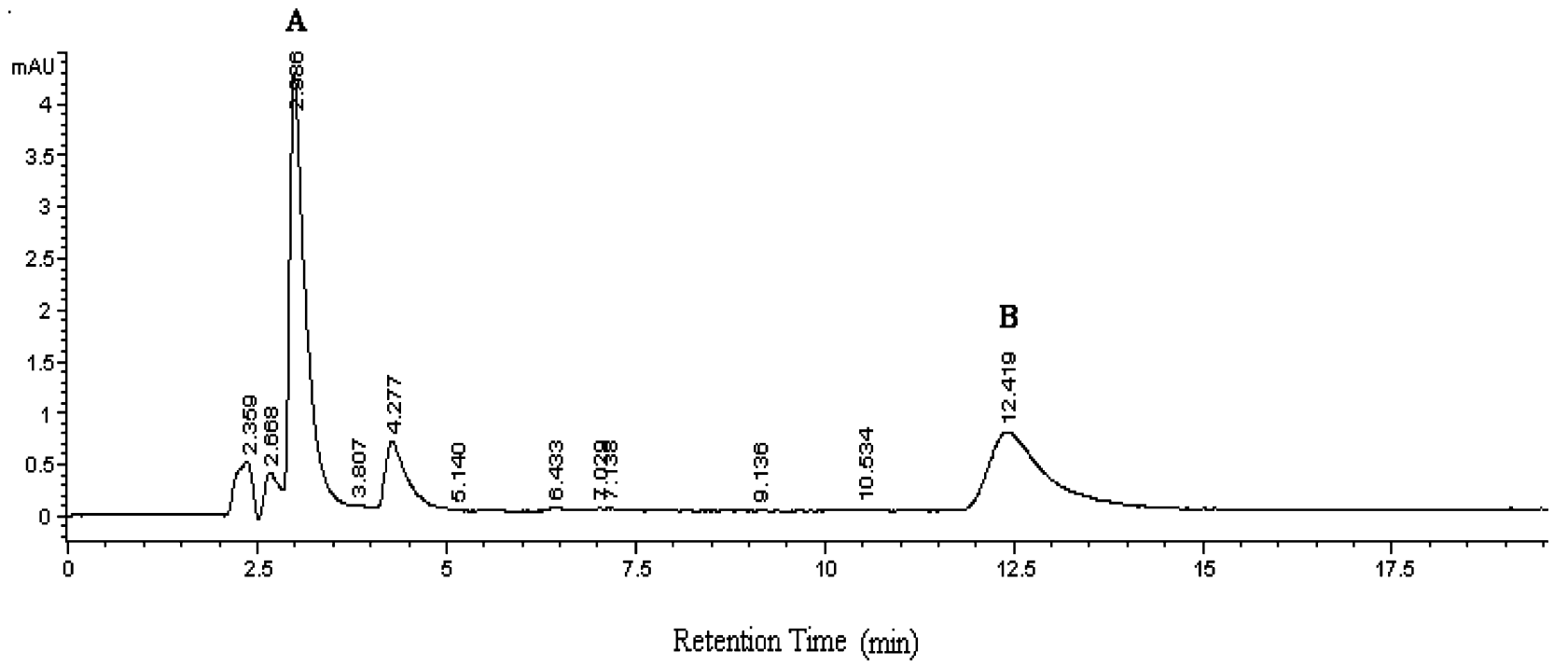

Figure 5. HPLC analysis of the metabolism products: PNP (A) and hydroquinone (B) during MP biodegradation in the coculture of $E$. coli $\mathrm{BL} 21$ and Ochrobactrum sp. strain LL-1.

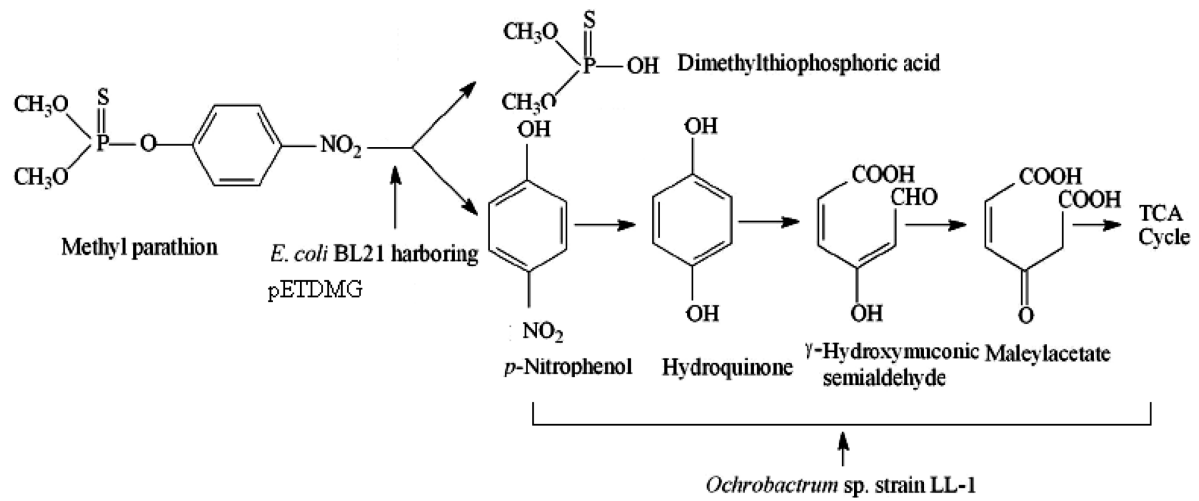

Figure 6. Proposed pathway for the biodegradation of MP by a constructed microbial consortium.

IPTG all other samples with different amounts of IPTG exhibited similar MPH activities and fluorescence intensity levels. These data suggest that maximum recombinant protein can be induced by $0.1 \mathrm{mM}$ IPTG.

Time-course studies of MPH activities and fluorescence intensity (Figure 2) were also carried out with $0.1 \mathrm{mM}$ IPTG at $30{ }^{\circ} \mathrm{C}$, with the same amount of cells $\left(\mathrm{OD}_{600}=1.0\right)$ being collected at $2 \mathrm{~h}$ intervals, and the corresponding enzyme activities determined. As shown in Figure 2, the MPH activity and fluorescence intensity of the cells containing pETDMG reached their maximum after induction for 6 and $8 \mathrm{~h}$, respectively. Moreover, the maximum of both MPH activities and fluorescence intensity in the pETDMG was $60-70 \%$ of that observed in bacteria expressing MPH or EGFP alone. This indicated a similar expression level of $m p d$ and egfp in the pETDMG plasmid.

Degradation of Different OP Residues on Vegetables by TCP of the GEM. As shown in Figure 3, all of the OP residues on cabbage leaves were degraded completely by MPH (TCP) in $100 \mathrm{~min}$ via hydrolysis of the phosphotriester bond. MP was quickly degraded within the first $20 \mathrm{~min}$. Complete hydrolysis of parathion, chlorpyrifos, and fenitrothion occurred within 60, 100 , and $80 \mathrm{~min}$, respectively. The hydrolysis rates are consistent with the kinetic properties of MPH, which are more efficient in hydrolyzing MP than other organophosphorus pesticides (6).

Effect of PNP on Growth and Metabolites of MP Degradation in Coculture. Because PNP is toxic to microbes and it can inhibit the growth of microbes (29), the growth rate of strain
BL21 could be inhibited with the accumulatation of PNP. As shown in Figure 4, only $32 \mu \mathrm{M}$ PNP was accumulated during the first $24 \mathrm{~h}$, and there was no obvious growth inhibition observed and in the coculture of strain E. coli BL21 and Ochrobactrum sp., which was subsequently degraded over the remainder of the experiment. PNP accumulated to a concentration of $82 \mu \mathrm{M}$ during growth as a batch monoculture of E. coli BL21 harboring pETDMG during the first $24 \mathrm{~h}$, and the concentration reached $183 \mu \mathrm{M}$ in $48 \mathrm{~h}$. The growth of E. coli would decrease gradually when concentrations of PNP were greater than $0.2 \mathrm{mM}$ and could be completely inhibited by 0.6 mM PNP (23). In the coculture, the PNP formed during MP hydrolysis could be rapidly degraded, and the inhibitory effect of PNP on the growth of E. coli BL21 could be eliminated by strain LL-1.

In the coculture, PNP and hydroquinone were detected by HPLC, while 4-nitrocatechol and 1,2,4-benzenetriol could not be detected (Figure 5). PNP is converted to hydroquinone or 1,2,4-benzenetriol in the process of metabolism in bacteria $(29,30)$. 4-Nitrocatechol and 1,2,4-benzenetriol are reported to be the major degradation products of PNP in Gram-positive bacteria (31). Hydroquinone is found to be the key catabolic intermediate of PNP in Gram-negative bacteria (29).

Our result demonstrated that MP could be degraded via the $\mathrm{MP} \rightarrow \mathrm{PNP} \rightarrow$ hydroquinone $\rightarrow$ TCA cycle (Figure 6) by the dual-species consortium. The data confirm that the process of mineralization of MP is initiated by hydrolysis leading to the 
generation of PNP and dimethylthiophosphoric acid, and PNP degradation then proceeds through the formation of hydroquinone.

\section{DISCUSSION}

A number of choices for coexpression of multiple target proteins in Escherichia coli are currently available $(31,32)$, of which the plasmid pETDuet has been designed for coexpression of two target genes. OPH and carboxylesterase B1 (33), as well as staphopain A and its inhibitor (34) were successfully coexpressed using the vector in E. coli BL-21 (DE3). The pETDuet vector contains two multiple cloning sites (MCS), each of which is preceded by a T7 promoter/lac operator and a ribosome binding site (RBS). In this work, two target genes of mpd and egfp were cloned downstream of $\mathrm{T} 7$ promoters of pETDuet. Coding regions of mpd and egfp are both controlled by $\mathrm{T} 7$ promoter in recombinant pETDMG. Meanwhile, to explore whether the differences between coexpression and expression alone would lead to a change in the activity of MPH or EGFP in the coexpression cells, the activity of MPH in coexpression cells were compared with that expressed alone, and at the same time, the same comparison was made for EGFP.

Hydrolysis of OPs by OPH or MPH can reduce mammalian toxicity by several orders of magnitude (35). MPH shares the broad substrate range of $\mathrm{OPH}$, which can catalyze the hydrolysis of many nerve agents and OPs. Besides, MPH has already been shown to have high hydrolytic activity toward numerous dimethyl OPs $(6,22)$. OPs that were applied in this study are diethyl compounds (chlorpyrifos and parathion) or dimethyl compounds (MP and fenitrothion). They have diethyl (or dimethyl) phosphorothionate side chains, and there was a phosphotriester bond in all compounds. MPH in the GEM showed high hydrolytic activity toward these OPs, which could be produced by high density batch fermentation and applied in detoxification of OP residues in food or vegetables.

Generally speaking, E. coli was not suitable to survive for a long time either in the environment or in a technical system. However, some studies about the coculture of E. coli and soildwelling bacteria in a laboratory study or field-scale remediation have been reported recently. A genetically engineered $E$. coli $\mathrm{DH} 5 \alpha$ overexpressing atrazine chlorohydrolase in a batch fermentor could significantly degrade atrazine using its wholecell suspension in heavily atrazine-contamined soil (36). A recent study found that Biofilm surface hydrophobicity and polymeric interactions made the E. coli JM109 cell able to survive and grow in porous media coated with Pseudomonas aeruginosa Biofilm with a relatively low nutrient supply (37). A consortium comprising E. coli DH10B and Pseudomonas putida KT2440 was cocultured as a Biofilm, and the two species could cohabit as a population of attached cells (23). In our work, further studies are required to examine whether the Biofilm could be formed by the two-species microbial consortium.

GFP is highly desirable as a cell marker because of several properties, high stability, minimal toxicity, noninvasive detection, and bright fluorescence without any requirements for additional substrates. GFP was used as a marker for expression of $\mathrm{OPH}$ in E. coli and later used as a fusion partner for the visualized degradation of paraoxon in a packed column (38-40). In this work, GFP was coexpressed with MPH in E. coli, and the fluorescence intensity in the coexpression system was $60-70 \%$ of that expressing EGFP alone. However, in a fusion expression or transposons system, the fluorescence intensity may significantly decrease. EGFP could be utilized as a cell marker of the dual-species consortium we developed in future bioreactor or field-scale remediation.
The dual-species consortium was developed for complete biodegradation of MP. One member of the consortium was responsible for hydrolyzing the parent compound, yielding two metabolites: PNP and dimethylthiophosphate. The other member of the consortium was responsible for mineralizing the stable intermediate PNP. However, additional research should be conducted on the kinetic analysis of the processes and the effect of spatial heterogeneity within the microbial community on biodegradation by the E. coli-Ochrobactrum consortium coculture. This will provide a basis for the research of a laboratoryscale bioreactor that we will develop to remove OP residues in wastewater or waste gas.

In summary, we genetically engineered $E$. coli to endow it with high MPH activity and fluorescence intensity using the pETDuet vector. Several widely used OP residues on vegetable material could effectively be removed by MPH expression in engineered E. coli. Moreover, a consortium with MP mineralizing activity was constructed by coculture of the engineered E. coli and a natural PNP degrader. The dual-species consortium possesses the enormous potential to be utilized for complete mineralization of PNP-substituted OPs in a laboratory-scale bioreactor.

\section{LITERATURE CITED}

(1) Zhang, R.; Cui, Z. L.; Jiang, J.; He, J.; Gu, X.; Li, S. P. Diversity of organophosphorus pesticide-degrading bacteria in a polluted soil and conservation of their organophosphorus hydrolase genes. Can. J. Microbiol. 2005, 51, 337-343.

(2) Mulbry, W. W.; Karns, J. S. Parathion hydrolase specified by the Flavobacterium opd gene: relationship between the gene and protein. J. Bacteriol. 1989, 171, 6740-6746.

(3) Serdar, C. M.; Murdock, D. C.; Rohde, M. F. Parathion hydrolase gene from Pseudomonas diminuta MG: subcloning, complete nucleotide sequence, and expression of the mature portion of the enzyme in Escherichia coli. Biotechnology 1989, 7, 1151-1155.

(4) Horne, I.; Sutherland, T. D.; Harcourt, R. L.; Russell, R. J.; Oakeshott, J. G. Identification of an opd (organophosphate degradation) gene in an Agrobacterium isolate. Appl. Environ. Microbiol. 2002, 68, 3371-3376.

(5) Cui, Z. L.; L,i, S. P.; Fu, G. P. Isolation of methyl parathiondegrading strain M6 and cloning of the methyl parathion hydrolase gene. Appl. Environ. Microbiol. 2001, 67, 4922-4925.

(6) Fu, G. P.; Cui, Z. L.; Huang, T.; L,i, S. P. Expression, purification, and characterization of a novel methyl parathion hydrolase. Protein Expression Purif. 2004, 36, 170-176.

(7) Yang, C.; Cai, N.; Dong, M.; Jiang, H.; Li, J.; Qiao, C. L.; Mulchandani, A.; Chen, W. Surface display of MPH on Pseudomonas putida JS444 using ice nucleation protein and its application in detoxification of organophosphates. Biotechnol. Bioeng. 2008, 99, 30-37.

(8) Cormack, B. P.; Valdivia, R. H.; Falkow, S. FACS-optimized mutants of the green fluorescent protein (GFP). Gene 1996, 173, 33-38.

(9) Nolte, C.; Matyash, M.; Pivneva, T.; Schipke, C. G; Ohlemeyer, C.; Hanisch, U. K; Kirchhoff, F.; Kettenmann, H. GFAP promoter controlled EGFP-expressing transgenic mice: a tool to visualize astrocytes and astrogliosis in living brain tissue. Glia 2001, 33, 72-86.

(10) Halfhill, M. D; Sutherland, J. P; Moon, H. S; Poppy, G. M.; Warwick, S. I.; Weissinger, A. K; Rufty, T. W.; Raymer, P. L.; Stewart, C N, Jr. Growth, productivity, and competitiveness of introgressed weedy Brassica rapa hybrids selected for the presence of Bt crylAc and gfp transgenes. Mol. Ecol. 2005, 14, 3177-3189.

(11) Jansson, J. K. Marker and reporter genes: Illuminating tools for environmental microbiologists. Curr. Opin. Microbiol. 2003, 6, 310-316.

(12) Tresse, O.; Errampalli, D.; Kostrzynska, M.; Leung, K. T.; Lee, H.; Trevors, J. T; Elsas, J. D. Green fluorescent protein as a visual 
marker in a p-nitrophenol degrading Moraxella sp. FEMS Microbiol. Lett. 1998, 164, 187-193.

(13) Errampalli, D.; Leung, K.; Cassidy, M. B.; Kostrzynska, M.; Blears, M.; Lee, H.; Trevors, J. T. Applications of the green fluorescent protein as a molecular marker in environmental microorganisms. J. Microbiol. Methods 1999, 35, 187-199.

(14) Li, C.; Zhu, Y.; Benz, I.; Schmidt, M. A.; Chen, W.; Mulchandani, A.; Qiao, C. L. Presentation of functional organophosphorus hydrolase fusions on the surface of Escherichia coli by the AIDA-I autotransporter pathway. Biotechnol. Bioeng. 2008, 99, 485-490.

(15) March, J. C.; Rao, G.; Bentley, W. E. Biotechnological applications of green fluorescent protein. Appl. Microbiol. Biotechnol. 2003, 62, 303-315.

(16) Gory, L.; Montel, M. C; Zagorec, M. Use of green fluorescent protein to monitor Lactobacillus sakei in fermented meat products. FEMS Microbiol. Lett. 2001, 194, 127-133.

(17) Chalova, V.; Woodward, C. L.; Ricke, S. C. Application of an Escherichia coli green fluorescent protein-based lysine biosensor under nonsterile conditions and autofluorescence background. Lett. Appl. Microbiol. 2006, 42, 265-270.

(18) Lei, Y.; Mulchandani, A.; Chen, W. Improved degradation of organophosphorus nerve agents and $p$-nitrophenol by Pseudomonas putida JS444 with surface-expressed organophosphorus hydrolase. Biotechnol. Prog. 2005, 21, 678-681.

(19) Richins, R. D; Kaneva, I.; Mulchandani, A.; Chen, W. Biodegradation of organophosphorus pesticides by surface-expressed organophosphorus hydrolase. Nat. Biotechnol. 1997, 15, 984-987.

(20) Shimazu, M.; Nuyen, A.; Mulchandani, A.; Chen, W. Cell surface display of organophosphorus hydrolase in Pseudomonas putida using ice nucleation protein anchor. Biotechnol. Prog. 2003, 19, $1612-1614$.

(21) Arfmann, H. A.; Timmis, K. N.; Wittich, R. M. Mineralization of 4-chlorodibenzofuran by a consortium consisting of Sphingomonas $s p$. strain RW1 and Burkholderia sp. strain JWS. Appl. Environ. Microbiol. 1997, 63, 3458-3462.

(22) Casellas, M.; Grifoll, M.; Sabata, J.; Solanas, A. M. Isolation and characterization of a 9-fluorenone-degrading bacterial strain and its role in synergistic degradation of fluorine by a consortium. Can. J. Microbiol. 1998, 44, 734-742.

(23) Gilbert, E. S.; Walker, A. W.; Keasling, J. D. A constructed microbial consortium for biodegradation of the organophosphorus insecticide parathion. Appl. Microbiol. Biotechnol. 2003, 61, 7781.

(24) Xu, G.; Li, Y.; Zheng, W.; Peng, X.; Li, W.; Yan, Y. Mineralization of chlorpyrifos by co-culture of Serratia and Trichosporon spp. Biotechnol. Lett. 2007, 29, 1469-1473.

(25) Yang, C.; Liu, N.; Guo, X. M.; Qiao, C. L. Cloning of $m p d$ gene from a chlorpyrifos-degrading bacterium and use of this strain in bioremediation of contaminated soil. FEMS Microbiol. Lett. 2006, $265,118-125$

(26) Sambrook, J.; Russel, D. W. Molecular Cloning: A Laboratory Manual, 3rd ed.; Cold Spring Harbor Laboratory Press: Cold Spring Harbor, NY, 2001.

(27) Bradford, M. M. A rapid and sensitive method for the quantification of microgram quantities of protein utilizing the principle of protein dye binding. Anal. Biochem. 1976, 72, 248-254.
(28) Qiu, X.; Bai, W.; Zhong, Q.; Li, M.; He, F.; Li, B. Isolation and characterization of a bacterial strain of the genus Ochrobactrum with methyl parathion mineralizing activity. J. Appl. Microbiol. 2006, 101, 986-994.

(29) Spain, J. C.; Gibson, D. T. Pathway for biodegradation of paranitrophenol in a Moraxella sp. Appl. Environ. Microbiol. 1991, $57,812-819$.

(30) Jain, R. K.; Dreisbach, J. H.; Spain, J. C. Biodegradation of p-nitrophenol via 1,2,4-benzenetriol by an Arthrobacter sp. Appl. Environ. Microbiol. 1994, 60, 3030-3032.

(31) Scheich, C.; Kümmel, D; Soumailakakis, D; Heinemann, U; Büssow, B. Vectors for co-expression of an unrestricted number of proteins. Nucleic Acids Res. 2007, 35, e43.

(32) Li, C.; Schwabe, J. W.; Banayo, E.; Evans, R. M. Coexpression of nuclear receptor partners increases their solubility and biological activities. Proc. Natl. Acad. Sci. U.S.A. 1997, 94, 2278-2283.

(33) Lan, W. S.; Gu, J. D; Shen, B. C; Jiang, H.; Qiao, C. L.; Mulchandani, A.; Chen, W. Coexpression of two detoxifying pesticide-degrading enzymes in a genetically engineered bacterium. In. Biodeterior. Biodegrad. 2006, 58, 70-76.

(34) Wladyka, B.; Puzia, K.; Dubin, A. Efficient co-expression of a recombinant staphopain $\mathrm{A}$ and its inhibitor staphostatin $\mathrm{A}$ in Escherichia coli. Biochem. J. 2005, 385, 181-187.

(35) Singh, B. K.; Walker, A. Microbial degradation of organophosphorus compounds. FEMS Microbiol. Rev. 2006, 30, 428-471.

(36) Strong, L. C.; McTavish, H.; Sadowsky, M. J.; Wackett, L. P. Field-scale remediation of atrazine-contaminated soil using recombinant Escherichia coli expressing atrazine chlorohydrolase. Environ. Microbiol. 2000, 2, 91-98.

(37) Liu, Y.; Li, J. Role of Pseudomonas aeruginosa Biofilm in the initial adhesion, growth and detachment of Escherichia coli in porous media. Environ. Sci. Technol. 2008, 42, 443-449.

(38) Cha, H. J; Wu, C. F.; Rao, G.; Valdes, J. J.; Bentley, W. E. Observations of green fluorescent protein as a fusion partner in genetically engineered Escherichia coli: monitoring protein expression and solubility. Biotechnol. Bioeng. 2000, 67, 565-574.

(39) Wu, C. F.; Cha, H. J; Rao, G.; Valdes, J. J.; Bentley, W. E. A green fluorescent protein fusion strategy for monitoring the expression, cellular location, and separation of biologically active organophosphorus hydrolase. Appl. Microbiol. Biotechnol. 2000, $54,78-83$.

(40) Wu, C. F.; Cha, H. J.; Valdes, J. J.; Bentley, W. E. GFP-visualized immobilized enzymes: Degradation of paraoxon via organophosphorus hydrolase in a packed column. Biotechnol. Bioeng. 2002, 77, 212-218.

Received for review February 22, 2008. Revised manuscript received July 16, 2008. Accepted July 16, 2008. This work was supported by grants from the Innovation Program of the Chinese Academy of Sciences (No. KSCX2-YW-G-008) and the 863 Hi-Tech Research and Development Program of the People's Republic of China (No. 2007AA06Z335).

JF801684G 